\title{
COVID-19: A Concern for Cardiovascular Disease Patients
}

\author{
Shruti Sharma ${ }^{1}$ \\ Received: 10 June 2020 / Accepted: 24 July 2020 / Published online: 29 July 2020 \\ (c) Springer Science+Business Media, LLC, part of Springer Nature 2020
}

\begin{abstract}
Coronavirus disease 2019 (COVID-19) is declared as a pandemic that has spread worldwide, affecting 205 countries. The disease affected 1, 40, 43, 176 individuals and caused 5, 97, 583 deaths around the globe. The organism responsible for the cause of disease is Severe Acute Respiratory Syndrome Coronavirus-2 (SARS-CoV-2). SARS-CoV-2 enters into the cell via receptors present on the cell surface named angiotensin-converting enzyme 2 (ACE2) receptor. Notwithstanding ACE2 receptors acts as a gateway for infection, and most of the cardiovascular patients are treated with the ACE inhibitors. Thus, the role of ACE inhibitors or angiotensin receptor blockers may play a critical role in the severity or outcome of disease. Also, the effect of ACE inhibitors varies with the polymorphism in ACE2 receptors present in the individuals. Hence, it is the need of the hour to investigate the mechanisms which could better aid in the treatment of COVID-19-infected cardiovascular disease (CVD) patients.
\end{abstract}

Keywords COVID-19 $\cdot$ SARS-CoV-2 $\cdot$ ACE2 receptors $\cdot$ CVD $\cdot$ Coronavirus

\section{Introduction}

Coronavirus Disease (COVID-19) is a recently emerged disease caused by Severe Acute Respiratory Syndrome Coronavirus-2 (SARS-CoV2), a novel coronavirus that leads to adverse pulmonary pathological features [1]. COVID-19 is a global pandemic as in total 205 countries have been affected by the disease around the world. There are 1, 40,43,176 confirmed cases worldwide and 5, 97, 583 deaths, as on July 19th, 2020 [2]. The chaotic situation began in China and the number of cases exceeded in other regions than those in China and is still currently rising. Furthermore, the number of fatalities in many other countries likes the USA, Brazil, and India has now exceeded the total in China. COVID-19 enhances morbidity in patients with cardiovascular diseases (CVDs) via interacting with the cardiovascular system on multiple levels, thereby, worsening the diseased conditions and leading to myocardial injury and dysfunction [1]. Due to such a high mortality and morbidity as well as widespread

Handling Editor: Matthew Campen.

Shruti Sharma

shrutisharma.8722@gmail.com

1 Department of Experimental Medicine and Biotechnology, Postgraduate Institute of Medical Education and Research, Sector -12, Chandigarh 160012, India occurrence, SARS-CoV2 should be eradicated from every part of the world.

Cardiovascular diseases (CVDs) are one of the major reasons of death globally, contributing to almost a third of total deaths [3]. However, proper attention has not been paid to CVD patients suffering from COVID-19. Various studies focusing on the clinical features of COVID-19 have not classified CVDs, but these CVDs might have links with prognosis of COVID-19. According to a study [4], out of 1099 COVID-19 cases, 173 suffered from comorbidities such as hypertension $(23.7 \%)$, coronary heart diseases $(5.8 \%)$, cerebrovascular disease (2.3\%), and diabetes mellitus (16.2\%). Notably, the most recurrent comorbidities demonstrated in these studies are often treated with angiotensin-converting enzyme (ACE) inhibitor. As, it has been demonstrated that the spike protein of SARS-CoV-2 helps in the viral entry inside the cell via ACE2 receptors present on the surface of epithelial cells of lung and other tissues [5], it can, therefore, be hypothesized that the levels of ACE2 are associated with SARS-CoV-2 infection susceptibility. Some of the studies have shown that ACE inhibitor improves the clinical outcome of COVID-19 patients with hypertension and recommends the continuation of these medicines [6,7]. Several other studies in this regard are ambiguous to the use of ACE inhibitors to manage hypertension in the setting of COVID19 [8,9]. Further, it has also been studied that the cellular 
ACE2 expression levels are not same in all individuals and polymorphisms of ACE2 may show effect on ACE2 levels [10]. Therefore, in the present review, the role of ACE2 receptors in the viral entry into the host cell, the effect of COVID-19 on the symptoms and prognosis of CVDs, impact of ACE inhibitors (ACEI), and angiotensin receptor blockers (ARBs) on patients of CVDs suffering from COVID-19 have been discussed. Further, the role of ACE2 genetic polymorphism in SARS-CoV-2 infection in CVD patients has been brought into light. Based on this information, modulation in ACE2 medications can be an alternative for the treatment of CVD patients infected with COVID-19.

\section{Origin of SARS-CoV-2}

The present pandemic of SARS-CoV-2 infection affected the health and economy worldwide. The first report came from the Wuhan Jinyintan hospital, China [11] and WHOled laboratory network made it possible to identify this virus as the causative agent of COVID-19. The properties like mutability and SARS-CoV genome open reading frames have contributed to the severe virulence of this virus [12].

The full-length genome sequencing of the virus demonstrates that this is a member of $\beta$-coronavirus $2 b$ lineage [13] and as it is not being detected in animals or humans previously, it is known as the so called novel corona virus. Being similar to the coronavirus responsible for severe acute respiratory syndrome (SARS-CoV), International Committee on Taxonomy of Viruses named it SARS-CoV-2 [14].

SARS-CoV-2, the causative organism for COVID-19, is a novel RNA virus with single positive strand. It is the seventh identified human coronavirus [15]. It is thought that this virus is originated in bats, like various other coronaviruses, since it shares 89-96\% nucleotide similarity with bat coronaviruses [16]. Like SARS and Middle East respiratory syndrome coronavirus (MERS-CoV), it is believed that it is transmitted from bats to human via an intermediate host (probably a Malayan Pangolin, which shares 91\% nucleotide homology) [17]. SARS-CoV-2 invades host cells via (ACE2) receptor via its spike protein [18]. The surface spike protein of the virus attaches to the human ACE2 receptor followed by the spike protein activation by transmembrane protease serine 2 (TMPRSS2). This protease cleaves the spike protein and brings about conformational changes in the spike protein that facilitates viral entry into the host cell [19].

Presently, the studies have shown that the range of incubation period of this virus is 1 to 14 days and the median is 5-6 days in most of the individuals; however, certain studies have shown that it may be upto 24 days [20]. The SARS$\mathrm{CoV}-2$ reproductive number (R0) comes out to be in between 2 and 3, suggesting that its pandemic potential is higher than SARS [21]. Although, the major symptoms are fever or cough, but most of the patients are asymptomatic [22]. At present, it is thought that the transmission of this virus is mainly via close contact and respiratory droplets; however, asymptomatic carrier may also be a souce of transmission [23]. Further, a study proposed that perinatal transmission is improbable; nonetheless, more studies are required to ensure this finding [24]. Similarly, transmission through fecal-oral route is yet to be established by further research [25].

\section{Adverse Cardiac Outcomes and COVID -19}

The most common affected organ in COVID-19 is lungs and results in pulmonary vascular endothelialitis, thrombosis, angiogenesis, interstitial pneumonitis, and severe acute respiratory distress syndrome [26]. Besides, multiple organs are also involved, particularly the cardiovascular system. Various cardiac complications like cardiovascular disease, arrhythmia (ventricular tachyarrhythmia, atrial fibrillation and ventricular fibrillation), hypertension, cardiac injury, heart failure, and fulminant myocarditis have been found to influence the mortality of the COVID -19 patients [27]. There is a higher prevalence of CVDs in COVID -19 patients and $7 \%$ of the patients experience myocardial injury (22\% of the critically ill). It is possible that the CVDs, such as ischemic heart disease, heart failure, and cardiac arrhythmia, may have different associations with prognosis of COVID-19. Fatigue and dyspnea and are the two cardinal symptoms of heart failure, which are generally present in COVID-19 patients, especially in severe condition [11]. Therefore, COVID-19 diagnosis in patients with chronic heart failure is a serious issue. Moreover, both heart failure and COVID-19 lead to hypoxemia that leads to death [28]. Nevertheless, proper attention has not been given to CVD patients having COVID-19. Furthermore, it has been demonstrated that the response of inflammatory reactions occurring in COVID-19 may cause the coronary plaques rupture in CAD patients [29]. The active COVID-19 patients may barely survive after a myocardial infarction. Notably, COVID-19-induced hypoxemia may, consequently, lead to atrial fibrillation, which could be intractable prior to the improvement in pulmonary function [30]. At present, the data concerning COVID-19 and cardiovascular complications is not sufficient [29]. According to a report, the heart failure was reported in 23\% of COVID patients admitted in hospital in China. Approximately $52 \%$ of non-survivors suffered from heart failure as compared with $12 \%$ of survivors [31]. According to a study by Wang et al. [32], acute cardiac injury or new abnormalities detected by echocardiography and electrocardiography has been reported in $7.2 \%$ of the COVID-19 patients. In addition, Guan et al. found that 90 of 675 (13.3\%) COVID-19 patients showed an increased creatinine kinase level and 277 of $675(41 \%)$ patients showed 
elevated lactate dehydrogenase level. Furthermore, arrhythmia has been observed in $16.7 \%$ of the patients. However, there is no clear categorization of parameters for arrhythmia and echocardiography [33]. As, SARS-CoV is considered as a sister to SARS-CoV-2 [34], there is a possibility of having similar effects on the heart by these two viruses. Yu et al., [35] observed that tachycardia in $71.9 \%$ and bradycardia in $14.9 \%$ were present transiently in COVID -19 patients. Consequently, common arrhythmia in COVID-19 patients might be tachycardia. Nevertheless, acute cardiac injury has been observed in 14\% of COVID-19 patients [11]. The cardiac injury might be due to hypoxemia, viral infection, or worsening of cardiac diseases. Furthermore, the pathological investigation from biopsy samples of COVID-19 cadaver indicated infiltration of myocardial interstitial by mononuclear inflammatory cells, without excessive injury to the heart tissue [36]. This observation indicates that myocarditis may be caused by SARS-CoV-2. It has been reported by $\mathrm{Li}$ et al. [37] that subclinical diastolic impairment is present in SARS patients that would reverse the clinical recovery of COVID-19 patients. However, no lymphocytic infiltration or myocytes necrosis has been observed in the patients' heart with the least ejection fraction of left ventricle [37]. Therefore, it has been hypothesized that these cardiac dysfunction may be indirect, caused by reduced oxygen supply, severe lung failure, and the systemic "cytokines storm" as a result of immune response by host to viral infection, where a number of cytokines, like tumor necrosis factor and the interleukin-6 family, have significant negative influence clinically. Further, whole-genome sequencing, cardiac magnetic resonance imaging, polymerase chain reaction, and culture of biopsy samples may confirm whether SARS-CoV-2 is present in the myocardium [34].

\section{ACE 2, Cardiovascular Disease, and COVID-19}

ACE2 receptors are abundantly present in the lungs and therefore are the pre-dominant gateway of entry of SARSCoV-2. ACE2 is abundantly present in the heart [38] as well, and it excessively activates the renin-angiotensin system (RAS) resulting in various cardiac complications such as congestive heart failure, hypertension, and atherosclerosis [39]. Besides the heart and lung, ACE2 receptors are also present in the vascular endothelium, intestinal epithelium, and the kidneys, thereby, leading to multi-organ dysfunction [40].

Recently, it has been revealed that SARS-CoV-2 binding affinity to ACE2 receptor is 10- to 20- fold elevated as compared to SARS-CoV, suggesting that human-to-human transmission of SARS-CoV-2 could be easily possible [29]. Angiotensin-converting enzyme inhibitors (ACEIs)/ angiotensin receptor blockers (ARBs) are majorly used for the treatment of CVDs. Notably, various reports have shown that ACEIs/ARBs upregulate ACE2 expression besides their key pharmacological effect, that is, inhibition of angiotensinconverting enzyme 1 (ACE1) or blocking angiotensin II type 1 receptor [41]. Thus, ACE2 may have contradictory roles in COVID- 19 patients, particularly those suffering from CVDs. ACE2 inhibitors may protect against hypertension, myocardial hypertrophy myocardial fibrosis, and arrhythmia, [42] along with acting as an entry gate for SARS-CoV-2 [34]. Previously, various studies have demonstrated that ACEI and ARB could enhance the ACE2 receptors expression [42]. It is, hence, reasonable to think, that treatment with ACEI/ARB might augment the SARS-CoV-2 infection risk. Conversely, reports illustrated that the ARB losartan and recombinant human ACE2 can protect experimental animal from severe lung injury. Taken into consideration that ACEI/ARB therapy is being given to patients with ischemic heart disease, hypertension, and heart failure, however, special consideration should be provided to patients with COVID-19 using ACEI/ARB therapy [32].

A further aspect that should be highlighted is the genetic polymorphism that might be one of the reasons for augmented risk of SARS-CoV-2 infection. There is a possibility that polymorphism in ACE2 gene, linked to hypertension, particularly, in Asian populations, affects the susceptibility of SARS-CoV-2 infection and COVID-19 disease outcome. It has been proposed that ACE2 gene polymorphisms may reduce the affinity of spike protein to the ACE2 receptors and lead to subsequent decreased susceptibility to SARSCOV 2 infection. On the basis of this information, the variability in rate of infection and/or lethality worldwide could be explained by ethnical/geographical variation of ACE 2 gene polymorphism [43].

Another study suggested that the genotypes of ACE2 gene polymorphism in different populations may be linked with higher ACE2 expression level [44]. Therefore, patients with cardiac diseases or hypertension, treated with the drugs that enhance the levels of ACE2 pose a greater risk for severe COVID-19 infection and, hence, should be recommended for ACE2-modulating medications [45].

Since ACE2 expression may associate with the susceptibility to infection of SARS-CoV- 2 and taking ACEIs/ ARBs may predispose CVD patients to the SARS-CoV- 2 infection, certain cardiologists may recommend that ACEIs/ARBs should be discontinued to avoid the potential risk of infection of SARS-CoV- 2. Even if so, it is demonstrated that the activation of RAS and ACE2 expression downregulation is implicated in SARS-CoV-2 infection-associated lung injury. It has also been demonstrated that serum level of angiotensin II is considerably increased in COVID-19 patients and showed an association with lung injury and viral load. The activation of RAS may cause extensive dysfunction of 
endothelial cells and varying degrees of multiple organ injuries [46].

Thus, intake of ACEIs/ARBs might probably decrease heart damage caused from the activation of RAS. These possibilities pose a dilemma for the cardiologists in terms of recommending whether to discontinue ACEIs/ARBs or not.

\section{Conclusion}

The association of CVDs with outcomes of COVID-19 is very complex and the scientific community has not yet arrived at any conclusion for the use of ACE inhibitors. Further, as various reports showed the comorbidities of CVDs and COVID-19, the ACE inhibitors should be used with preventative measures. In addition, the association of ACE polymorphism and the COVID-19 outcome in the CVD patients should be studied in a large cohort to identify the role of ACE polymorphism in the prognosis and outcome of the COVID-19 in CVD patients using ACEIs/ARBs.

\section{Compliance with Ethical Standards}

Conflict of interest The author declares that she has no conflict of interest.

Ethical Approval This article does not contain any studies with human participants or animals performed by the author. Therefore, informed consent is not required.

\section{References}

1. Clerkin, K. J., Fried, J. A., Raikhelkar, J., Sayer, G., Griffin, J. M., Masoumi, A., et al. (2020). Coronavirus disease 2019 (COVID-19) and cardiovascular disease. Circulation. https://doi. org/10.1161/CIRCULATIONAHA.120.046941.

2. Novel Coronavirus (2019-nCoV) situation reports-181; World Health Organization. https://www.who.int/docs/default-source/ coronaviruse/situation-reports/20200719-covid-19-sitrep-181. pdf?sfvrsn=82352496_2.

3. Benjamin, E. J., Blaha, M. J., Chiuve, S. E., Cushman, M., Das, S. R., Deo, R., et al. (2017). Heart disease and stroke statistics-2017 update: A report from the American Heart Association. Circulation, 135, e146-e603. https://doi.org/10.1161/CIR.0000000000 000485 .

4. Guan, W., Ni, Z., Hu, Y., Liang, W. H., Ou, C. Q., He, J. X., et al. (2020). Clinical characteristics of coronavirus disease 2019 in China. The New England Journal of Medicine. https://doi. org/10.1056/NEJMoa2002032.

5. Qiu, Y., Zhao, Y. B., Wang, Q., Li, J. Y., Zhou, Z. J., Liao, C. H., et al. (2020). Predicting the angiotensin converting enzyme 2 (ACE2) utilizing capability as the receptor of SARS-CoV-2. Clinical Microbiology and Infection. https://doi.org/10.1016/j. micinf.2020.03.003003.

6. Meng, J., Xiao, G., Zhang, J., He, X., Ou, M., Bi, J., et al. (2020). Renin-angiotensin system inhibitors improve the clinical outcomes of COVID-19 patients with hypertension. Emerging Microbes \& Infections, 9, 757-760. https://doi.org/10.1080/22221 751.2020 .1746200 .

7. Talreja, H., Tan, J., Dawes, M., Supershad, S., Rabindranath, K., Fisher, J., et al. (2020). A consensus statement on the use of angiotensin receptor blockers and angiotensin converting enzyme inhibitors in relation to COVID-19 (corona virus disease 2019). New Zealand Medical Journal, 133, 85-87.

8. Patel, A. B., \& Verma, A. (2020). COVID-19 and angiotensin-converting enzyme inhibitors and angiotensin receptor blockers: What is the evidence? JAMA. https://doi.org/10.1001/jama.2020.4812.

9. Sommerstein, R., Kochen, M. M., Messerli, F. H., \& Gräni, C. (2020). Coronavirus disease 2019 (COVID-19): Do angiotensinconverting enzyme inhibitors/angiotensin receptor blockers have a biphasic effect? Journal of the American Heart Association, 9, e016509. https://doi.org/10.1161/JAHA.120.016509.

10. Devaux, C. A., Rolain, J. M., \& Raoult, D. (2020). ACE2 receptor polymorphism: Susceptibility to SARS-CoV-2, hypertension, multi-organ failure, and COVID-19 disease outcome. Journal of Microbiology, Immunology, and Infection, 53, 425-435. https:// doi.org/10.1016/j.jmii.2020.04.015.

11. Huang, C., Wang, Y., Li, X., Ren, L., Zhao, J., Hu, Y., et al. (2020). Clinical features of patients infected with 2019 novel coronavirus in Wuhan, China. Lancet (London England), 395, 497-506. https://doi.org/10.1016/s0140-6736(20)30183-5.

12. Groneberg, D. A., Hilgenfeld, R., \& Zabel, P. (2005). Molecular mechanisms of severe acute respiratory syndrome (SARS). Respiratory Research, 6, 8. https://doi.org/10.1186/1465-9921-6-8.

13. Zhu, N., Zhang, D., Wang, W., Li, X., Yang, B., Song, J., et al. (2020). A novel coronavirus from patients with pneumonia in China, 2019. The New England Journal of Medicine, 382, 727733. https://doi.org/10.1056/NEJMoa2001017Feb20.

14. Coronaviridae Study Group of the International Committee on Taxonomy of Viruses. (2020). The species severe acute respiratory syndrome-related coronavirus: Classifying 2019-nCoV and naming it SARS-CoV-2. Nature Microbiology. https://doi. org/10.1038/s41564-020-0695-z.

15. Badawi, A., \& Ryoo, S. G. (2016). Prevalence of comorbidities in the Middle East respiratory syndrome coronavirus (MERS-CoV): A systematic review and meta-analysis. International Journal of Infectious Diseases, 49, 129-133. https://doi.org/10.1016/j. ijid.2016.06.015.

16. Andersen, K. G., Rambaut, A., Lipkin, W. I., Holmes, E. C., \& Garry, R. F. (2020). The proximal origin of SARS-CoV-2. Nature Medicine. https://doi.org/10.1038/s41591-020-0820-9.

17. Zhang, T. W. Q., \& Zhang, Z. (2020). Probable pangolin origin of SARS-CoV-2 associated with the COVID-19 outbreak. Current Biology. https://doi.org/10.1016/j.cub.2020.03.022.

18. Shang, J., Ye, G., Shi, K., Wan, Y., Luo, C., Aihara, H., et al. (2020). Structural basis of receptor recognition by SARS-CoV-2. Nature. https://doi.org/10.1038/s41586-020-2179-y.

19. Hoffmann, M., Kleine-Weber, H., Schroeder, S., Krüger, N., Herrler, T., Erichsen, S., et al. (2020). SARS-CoV-2 cell entry depends on ACE2 and TMPRSS2 and is blocked by a clinically proven protease inhibitor. Cell. https://doi.org/10.1016/j. cell.2020.02.052.

20. Guan, W. J., Ni, Z. Y., Hu, Y., et al. (2020). Clinical characteristics of coronavirus disease 2019 in China. New England Journal of Medicine. https://doi.org/10.1056/NEJMoa2002032Feb28.

21. Hellewell, J., Abbott, S., Gimma, A., Bosse, N. I., Jarvis, C. I., Russell, T. W., et al. (2020). Feasibility of controlling COVID19 outbreaks by isolation of cases and contacts. Lancet Global Health. https://doi.org/10.1016/s2214-109x(20)30074-7.

22. Bai, Y., Yao, L., Wei, T., Tian, F., Jin, D. Y., Chen, L., et al. (2020). Presumed asymptomatic carrier transmission of COVID19. JAMA. https://doi.org/10.1001/jama.2020.2565. 
23. Pan, Y., Zhang, D., Yang, P., Poon, L. L. M., \& Wang, Q. (2020). Viral load of SARS-CoV-2 in clinical samples. Lancet Infectious Diseases. https://doi.org/10.1016/s1473-3099(20)30113-4.

24. Chen, H., Guo, J., Wang, C., Luo, F., Yu, X., Zhanget, W., et al. (2020). Clinical characteristics and intrauterine vertical transmission potential of COVID-19 infection in nine pregnant women: A retrospective review of medical records. Lancet. https://doi. org/10.1016/s0140-6736(20)30360-3.

25. Zhang, W., Du, R. H., Li, B., et al. (2020). Molecular and serological investigation of 2019- nCoV infected patients: Implication of multiple shedding routes. Emerging Microbes \& Infections, 9, 386-389. https://doi.org/10.1080/22221751.2020.1729071.

26. Ackermann, M., Verleden, S. E., Kuehnel, M., et al. (2020). Pulmonary vascular endothelialitis, thrombosis, and angiogenesis in covid-19. New England Journal of Medicine, 383, 120-128. https ://doi.org/10.1056/NEJMoa2015432.

27. Guzik, T. J., Mohiddin, S. A., Dimarco, A., Patel, V., Savvatis, K., Marelli-Berget, F. M., et al. (2020). COVID-19 and the cardiovascular system: Implications for risk assessment, diagnosis, and treatment options. Cardiovascular Research. https://doi. org/10.1093/cvr/cvaa106.

28. Chen, N., Zhou, M., Dong, X., Qu, J., Gong, F., Han, Y., et al. (2020). Epidemiological and clinical characteristics of 99 cases of 2019 novel coronavirus pneumonia in Wuhan, China: A descriptive study. Lancet, 395, 507-513. https://doi.org/10.1016/S0140 -6736(20)30211-7.

29. Yang, C., \& Jin, Z. (2020). An acute respiratory infection runs into the most common noncommunicable epidemic-COVID-19 and cardiovascular diseases. JAMA Cardiology. https://doi. org/10.1001/jamacardio.2020.0934.

30. Madjid, M., Safavi-Naeini, P., Solomon, S. D., \& Vardeny, O. (2020). Potential effects of coronaviruses on the cardiovascular system: A review. JAMA Cardiology. https://doi.org/10.1001/ jamacardio.2020.1286.

31. Zhou, F., Yu, T., Du, R., Fan, G., Liu, Y., Liu, Z., et al. (2020). Clinical course and risk factors for mortality of adult inpatients with COVID-19 in Wuhan, China: A retrospective cohort study. Lancet, 395, 1054-1062. https://doi.org/10.1016/S0140 -6736(20)30566-3.

32. Wang, D., Hu, B., Hu, C., Zhu, F., Liu, X., Zhang, J., et al. (2020). Clinical characteristics of 138 hospitalized patients with 2019 novel coronavirus infected pneumonia in Wuhan, China. JAMA. https://doi.org/10.1001/jama.2020.1585.

33. Guan, W. J., Ni, Z. Y., Hu, Y., Hu, Y., Liang, W. H., Ou, C. Q., et al. (2020). China medical treatment expert group for covid19. Clinical characteristics of coronavirus disease 2019 in China. The New England Journal of Medicine. https://doi.org/10.1056/ NEJMoa2002032.

34. Wrapp, D., Wang, N., Corbett, K. S., Goldsmith, J. A., Hsieh, C. L., Abiona, O., et al. (2020). Cryo-EM structure of the 2019nCoV spike in the prefusion conformation. Science. https://doi. org/10.1126/science.abb2507.

35. Yu, C. M., Wong, R. S., Wu, E. B., Kong, S. L., Wong, J., Yip, G. W., et al. (2006). Cardiovascular complications of severe acute respiratory syndrome. Postgraduate Medical Journal, 82, 140144. https://doi.org/10.1136/pgmj.2005.037515.
36. Xu, Z., Shi, L., Wang, Y., Zhang, J., Huang, L., Zhang, C., et al. (2020). Pathological findings of COVID-19 associated with acute respiratory distress syndrome. The Lancet Respiratory Medicine, 20, S2213-2600. https://doi.org/10.1016/S2213-2600(20)30076 -X.

37. Li, S. S., Cheng, C. W., Fu, C. L., Chan, Y. H., Lee, M. P., Chan, J. W., et al. (2003). Left ventricular performance in patients with severe acute respiratory syndrome. Circulation, 108, 1798-1803. https://doi.org/10.1161/01.CIR.0000094737.21775.32.

38. Chen, L., Li, X., Chen, M., Feng, Y., \& Xiong, C. (2020). The ACE2 expression in human heart indicates new potential mechanism of heart injury amongng patients infected with SARSCoV-2. Cardiovascular Research, 116, 1097-1100. https://doi. org/10.1093/cvr/cvaa078.

39. Tikellis, C., \& Thomas, M. C. (2012). Angiotensin-converting enzyme 2 (ACE2) is a key modulator of the renin angiotensin system in health and disease. International Journal of Peptide Research, 2012, 256294. https://doi.org/10.1155/2012/256294.

40. Zhang, H., Penninger, J. M., Li, Y., Zhong, N., \& Slutsky, A. S. (2020). Angiotensin-converting enzyme 2 (ACE2) as a SARSCoV-2 receptor: Molecular mechanisms and potential therapeutic target. Intensive Care Medicine. https://doi.org/10.1007/s0013 4-020-05985-9.

41. Ferrario, C. M., Jessup, J., Chappell, M. C., Averill, D. B., Brosnihan, K. B., Tallant, E. A., et al. (2005). Effect of angiotensinconverting enzyme inhibition and angiotensin II receptor blockers on cardiac angiotensin-converting enzyme 2. Circulation, 111, 2605-2610.

42. Patel, V. B., Zhong, J. C., Grant, M. B., \& Oudit, G. Y. (2016). Role of the ACE2/angiotensin 1-7 axis of the renin-angiotensin system in heart failure. Circulation Research, 118, 1313-1326. https://doi.org/10.1161/CIRCRESAHA.116.307708.

43. Alifano, M., Alifano, P., Forgez, P., \& Iannelli, A. (2020). Reninangiotensin system at the heart of COVID-19 pandemic. Biochimie, 174, 30-33. https://doi.org/10.1016/j.biochi.2020.04.008.

44. Cao, Y., Li, L., Feng, Z., Wan, S., Huang, P., Sun, X., et al. (2020). Comparative genetic analysis of the novel coronavirus (2019nCoV/SARS-CoV-2) receptor ACE2 in different populations. Cell Discovery, 6, 11. https://doi.org/10.1038/s41421-020-0147-1.

45. Fang, L., Karakiulakis, G., \& Roth, M. (2020). Are patients with hypertension and diabetes mellitus at increased risk for COVID19 infection? Lancet Respiratory Medicine, 8, e21. https://doi. org/10.1016/S2213-2600(20)30116-8.

46. Guo, J., Huang, Z., Lin, L., \& Lv, J. (2020). Coronavirus disease 2019 (COVID-19) and cardiovascular disease: A viewpoint on the potential influence of angiotensin-converting enzyme inhibitors/angiotensin receptor blockers on onset and severity of severe acute respiratory syndrome coronavirus 2 infection. Journal of the American Heart Association, 9, e016219. https://doi.org/10.1161/ JAHA.120.016219.

Publisher's Note Springer Nature remains neutral with regard to jurisdictional claims in published maps and institutional affiliations. 